\title{
Family Dysfunction and Self-Medication for Acute Febrile IIIness
}

\author{
Alexander Adelabu Azonobo *, Musa Dankyau \\ Department of Family Medicine, Bingham University Teaching Hospital, Jos, Nigeria \\ Email address: \\ divineheritagecare@gmail.com (A. A. Azonobo),dankyau@gmail.com (M. Dankyau) \\ ${ }^{*}$ Corresponding author
}

To cite this article:

Alexander Adelabu Azonobo, Musa Dankyau. Family Dysfunction and Self-Medication for Acute Febrile Illness. Journal of Family Medicine and Health Care. Vol. 2, No. 4, 2016, pp. 114-118. doi: 10.11648/j.jfmhc.20160204.24

Received: September 2, 2016; Accepted: October 29, 2016; Published: December 12, 2016

\begin{abstract}
Background: Fever is a common complain from patients globally. Self medication for acute febrile illness is also a common practice but often with severe consequences. The family influences the health of the individuals and hence the community in several ways. Family function has major influence on decisons made at home including health seeking behaviour. Objectives: This study set out to determine the relationship between family function and self medication for acute febrile illness in a primary care setting in Jos, in order to proffer solutions to irresponsible and dangerous practices. Methods: It was a cross-sectional study at the GOPD of Bingham University Teaching Hospital (BHUTH), Jos from October 2012 to February 2013. The study population comprised all patients who presented at the study site with fever or history of fever of not more than two weeks duration and who met the inclusion criteria. Data was collected with interviewer-administered structured questionaire and analysed with the Statistical Program for Social Science (SPSS), version 21. Results: The study revealed a high level of self medication (85.0\%) in the study population. Most $(92.5 \%)$ of the participants were from highly functional families. There was a statistically significant relationship between family dysfunction and self medication for acute febrile illness. Conclusion: There is a high level of self medication among the study population. Although highly functional families were in the majority, family dysfunction was significantly related to self medication.
\end{abstract}

Keywords: Family Function, Dysfunctional Family, Family APGAR, Self-medication, Fever

\section{Introduction}

Self-medication has been a feature of healthcare for many years. [1] Self-care, including appropriate self-medication, can promote early and judicious response to diseases. [1, 2] Selfmedication commonly utilizes over the counter medications (OTC), but where drug distribution controls are weak, patients may buy classified medications from numerous outlets. [3]

Fever is a common feature of many diseases and is a symptom that is particularly linked to self-medication prior to health facility visits. [4-6] This reveals a decision-making process among caregivers $[7,8]$ that can provide a foundation for health education on safe and effective home-treatment practices.

The family remains the most basic relational unit and intimate social environment in society. [9] The family also has a major influence on the physical and mental health of its members, [10] and is often the primary source of health beliefs and health-related behaviors.

Family practice focuses on the patient in the context of the family. By understanding how the family influences health, the family physician has the opportunity to anticipate and reduce the adverse effects of family stress, and use the family as a resource in patient care. [11] A family-oriented approach to health care is based on the biopsychosocial model that emphasizes the relationship between biologic, interpersonal and social factors in health. [12]

A better understanding of health-seeking behavior of people especially when suffering from acute fever, a common symptom of malaria, is important for effective management and control of malaria. [13] It is documented that selftreatment at home is the major action taken to manage malaria, a common cause of acute febrile illness. [14] Chukwuocha and Chukwuocha in a review of the continued relevance of home management of malaria strategy in the 
effective and sustainable control of malaria in endemic areas noted that a mother's/caregiver's knowledge and ability to recognize fever in their child, as well as, induce management at home is very important. [15] Also, the direct and especially indirect costs of seeking health care from formal facilities may be substantial, providing a major barrier for many households. Many episodes of malaria are currently treated outside the formal health system, often with inappropriate or incorrectly used drugs. [15]

The family is the basic unit of the society and harmonious, functional families contribute to the same attributes in the larger society. A dysfunctional family on the other hand is associated with crises, strife, addictions and other health related and social vices in one or more members of such a family. This sort of family also contributes these negative attributes to the larger society.

In acute febrile illness, medication is a major intervention. Access to this important intervention is often haphazard and fraught with unintended complications. The decision to selfmedicate is often made at family level at home. [13] Even when it is self-made, it is either funded by a parent, encouraged by a spouse, aided by a child who may run the errand to purchase it, or supported by a neighbor who may generously donate the drug. Therefore, a better understanding of the self-medicating individual against the background of the family is very important in managing this problem in the larger society.

A dysfunctional family is one in which conflict, misbehaviors and often abuse on the part of individual members occur continually and regularly, leading other members to accommodate such actions. [16] Dysfunctional families are primarily a result of co-dependent adults who by accommodating each other's misbehaviours, promote and depend on each other to perpetuate them. [16] Each finds what he or she does quite objectionable in the larger society but they are left with learning to live with each other and the abuses. Dysfunctional families may also be affected by addiction such as substance abuse (alcohol, drugs, etc.). Children from such families suffer from addiction to smoking, alcohol and/or drugs, especially if the parents or friends have done same. [16]

The family APGAR questionnaire is used to assess family function. The scores and interpretation are as follows:

7-10: Highly functional family.

4-6: Moderately dysfunctional family.

0-3: Severely dysfunctional family.

This study aims to highlight family dynamics in relationship to self-medication for acute febrile illness with a view to discouraging dangerous practices and streamline responsible self-medication.

\section{Methodology}

\section{STUDY AREA}

This study was conducted at the Bingham University Teaching Hospital (BHUTH) Jos. Jos is the capital of Plateau state, North central Nigeria. It was a correlational cross sectional study of all patients presenting with fever or history of fever at the general out-patient clinic of Bingham University Teaching Hospital (BHUTH) Jos between October 2012 and February 2013.

Approval to conduct the study was obtained from the Health Research Ethics Committee of Bingham University Teaching Hospital, Jos. All participants gave informed consent.

We included all consenting patients presenting with a temperature of $37.5^{\circ} \mathrm{C}$ or more on presentation, or a history of fever not more than two weeks' duration. Patients needing urgent surgical intervention, or who were unable to communicate in English language, or any of the eight languages for which there were available interpreters were excluded.

Sample size was calculated using the formula: [17]

$$
\begin{gathered}
\mathrm{n}=\mathrm{Z}^{2} \mathrm{pq} / \mathrm{d}^{2} \\
\mathrm{n}=\frac{(1.96)^{2} \quad(0.50) \quad(0.50)}{(0.05)^{2}}=384
\end{gathered}
$$

To provide for possible non-response, $5 \%$ of $n$ was added i.e. $384+19=403$.

Sample size $=403$.

After correction for a population less than 10,000, [17] the desired sample size,

$$
\mathrm{nf}=\frac{\mathrm{n}}{1+\frac{(\mathrm{n})}{(\mathrm{N})}}=308 .
$$

Consenting participants were recruited by systematic random sampling technique until the sample size was attained. For patients who were less than 18 years of age, their caregivers constituted the respondents.

Data for the research was obtained from the respondents using an interviewer-administered, semi structured questionaire. Data collected was entered into a prepared data sheet in SPSS version 21, for analysis.

\section{Results}

Out of 3620 patients who presented at the GOPD, 1506 $(41.6 \%)$ had fever for less than two weeks. Of these, 1420 $(94.3 \%)$ met the inclusion criteria and were given the opening statement. 1232 (86.8\%) gave consent for the study, and from this group, a sample of 308 was taken.

Respondents were mostly patients $(51.6 \%)$, and $60 \%$ were in the age group 21-40 years. They were for the most part females $(53.2 \%)$, had tertiary education $(48.4 \%)$, and married $(79.2 \%)$. Almost $80 \%$ of the families of the respondents were in the two lowest income groups earning less than $\$ 50,000$ a month. Other details are in Table 1

Table 1. Demographic characteristics of respondents.

\begin{tabular}{llll}
\hline Demographic characteristics & $\begin{array}{l}\text { Frequency } \\
(\mathbf{N = 3 0 8 )}\end{array}$ & Percentage (\%) \\
\hline Status of & Patient & 159 & 51.6 \\
respondent & Caregiver & 149 & 48.4 \\
& $\leq 20$ & 38 & 12.3 \\
\multirow{4}{*}{ Age group } & $21-30$ & 90 & 29.2 \\
& $31-40$ & 88 & 28.6 \\
& $41-50$ & 51 & 16.6 \\
\hline
\end{tabular}




\begin{tabular}{llll}
\hline Demographic characteristics & $\begin{array}{l}\text { Frequency } \\
(\mathbf{N}=\mathbf{3 0 8})\end{array}$ & Percentage (\%) \\
\hline \multirow{4}{*}{ Gender } & $>50$ & 41 & 13.3 \\
& Male & 144 & 46.8 \\
& Female & 164 & 53.2 \\
& None & 25 & 8.1 \\
Education & Primary & 38 & 12.3 \\
& Secondary & 96 & 31.2 \\
& Tertiary & 149 & 48.4 \\
Religion & Christianity & 273 & 88.6 \\
& Islam & 35 & 11.4 \\
Marital status & Single & 64 & 20.8 \\
& Married & 244 & 79.2 \\
& Civil servant & 90 & 39.0 \\
& Trader & 72 & 31.2 \\
Occupation & House wife & 44 & 19.0 \\
& Unemployed & 16 & 6.9 \\
& Professional & 9 & 3.9 \\
& $\leq 25,000$ & 116 & 37.7 \\
Income per & $25,001-50,000$ & 122 & 39.6 \\
Month (\#) & $50,001-75,000$ & 29 & 9.6 \\
& $75,001-100,000$ & 18 & 5.8 \\
& $>100,000$ & 23 & 7.5 \\
\hline
\end{tabular}

The commonest Stevenson family stages were I (emerging family, 35.4\%) and IV (actualizing family, 31.2\%).

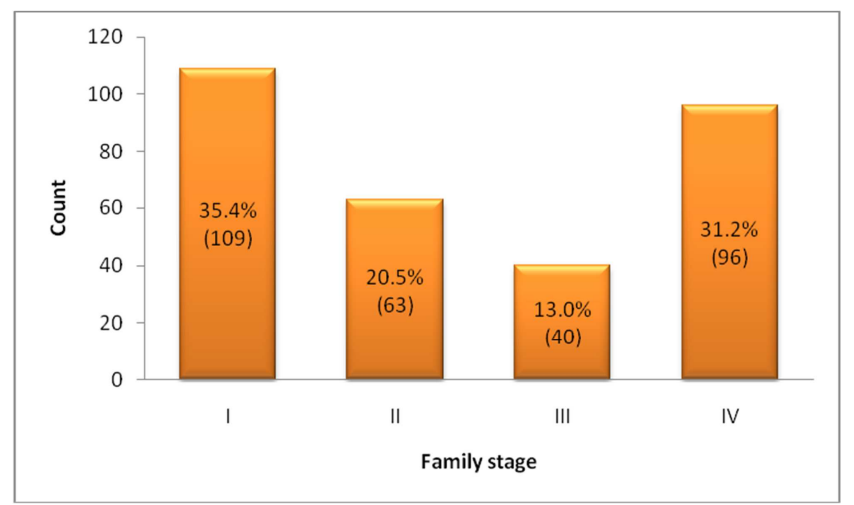

Figure 1. Bar chart of Stevenson's family stage distribution of respondents.

Based on the Family APGAR scores, majority of the families $(92.5 \%)$ were highly functional and only two families representing $0.6 \%$ were severely dysfunctional.

Table 2. Family function category based on APGAR scores.

\begin{tabular}{lll}
\hline Family function & Frequency $(\mathbf{N})$ & Percentage (\%) \\
\hline Highly functional & 285 & 92.5 \\
Moderately dysfunctional & 21 & 6.8 \\
Severely dysfunctional & 2 & 0.6 \\
Total & 308 & 100.0 \\
\hline
\end{tabular}

Relationship between family function and self-medication in acute febrile illness. All respondents who were from dysfunctional families self medicated, in contrast to those from highly functional families. The difference was statistically significant $(\mathrm{P}=0.037)$.
Table 3. Relationship between family function and self-medication in acute febrile illness.

\begin{tabular}{llll}
\hline Family function & \multicolumn{2}{l}{ Self-medication } & \\
\hline & Yes & No & P \\
\hline Highly functional & $239(83.9)$ & $46(16.1)$ & 0.037 \\
*Dysfunctional & $23(100.0)$ & $0(0.0)$ & \\
Total & $262(85.1)$ & $46(14.9)$ & \\
\hline
\end{tabular}

Test statistics is Chi square $\left(\mathrm{x}^{2}\right)$.

*dysfunctional $=$ moderately dysfunctional + severely dysfunctional by family Apgar.

Relationship between family size and self medication. Those respondents from smaller family sizes were generally more likely to engage in self medication but the differences were not statistically significant $(\mathrm{P}=0.227)$.

Table 4. Relationship between family size and self medication.

\begin{tabular}{llll}
\hline Family size & Self medication & P \\
\hline & Yes & No & \\
\hline $1-5$ & $124(86.7)$ & $19(13.3)$ & 0.227 \\
$6-10$ & $112(86.2)$ & $18(13.6)$ & \\
$11-15$ & $11(68.8)$ & $5(31.3)$ & \\
$>15$ & $15(78.9)$ & $4(21.1)$ & \\
Total & $262(85.1)$ & $46(14.9)$ & \\
\hline
\end{tabular}

Test statistics is Chi square $\left(\mathrm{x}^{2}\right)$.

Multiple logistic regression of family factors related to self-medication. Dysfunctional families were more likely to engage in self-medication than highly functional families $(\mathrm{P}=0.037$. OR 1.0).

Table 5. Multiple logistic regression of factors predicting self medication.

\begin{tabular}{llll}
\hline Variables & & P & OR (95\% CI) \\
\hline \multirow{2}{*}{ Family stage } & I & & $0.1(0.0-0.5)$ \\
& II & 0.185 & $0.2(0.0-1.1)$ \\
& III & & $0.4(0.1-2.8)$ \\
& IV & & 1.0 \\
Family size & $1-5$ & & $1.7(0.5-5.8)$ \\
& $6-10$ & 0.227 & $1.6(0.4-5.6)$ \\
& $11-15$ & & $0.6(0.1-2.7)$ \\
& $>15$ & & 1.0 \\
Income & $\leq 25,000$ & & $0.2(0.0-1.4)$ \\
& $25,001-50,000$ & 0.239 & $0.3(0.0-2.6)$ \\
& $50,001-75,000$ & & $0.4(0.0-4.1)$ \\
& $75,001-100,000$ & & $0.2(0.0-2.4)$ \\
Family function & Highly functional & \multirow{2}{*}{0.037} & $0.9(0.8-1.0)$ \\
& $*$ Dysfunctional & & 1.0 \\
\hline
\end{tabular}

*(Severely + Moderately dysfunctional)

\section{Discussion}

This was a cross sectional study of family factors affecting self medication in acute febrile illness in patients presenting in a family medicine practice in Jos, Nigeria. The main research question was: "does family function affect patient self medication for acute febrile illness at the General Out Patient Department of Bingham University Teaching Hospital?" 
Patients constituted $51.6 \%$ of respondent and care givers, $48.4 \%$. The care givers responded on behalf of patients who were less than 18 years of age. These care givers were senior family members. It has been reported that the family has a major influence on decisions about the health of an individual. [10, 15, 18] Family influence goes beyond the actual time of the visit, and include decisions taken before and after hospital encounter. In the Indian state of Haryana, Paine et al found $73.6 \%$ patient respondents and $26.4 \%$ care givers. [19] These care givers were messengers who often ran errands to procure the drug for self medication. The high proportion of patient respondents in the Haryana study was probably due to the fact that respondents were primarily recruited in the community pharmacies where they accessed drugs for self medication.

\section{Family and Self Medication Practice}

Majority $(66.6 \%)$ of the respondents were in Stevenson's stage I, (35.4\%) and IV (31.2\%) families. These were the emerging and actualising families. This could be a reflection of the predominant age group of 20 to 40 years on one hand and the $48.4 \%$ respondents who were caregivers, likely elderly parents or grand parents on the other hand.

The results also showed that $92.5 \%$ of the families were highly functional, $6.8 \%$ were moderately dysfunctional while two families representing $0.6 \%$ were severely dysfunctional. The high level of highly functional families could reflect the well known traditional African family set up where everyone is his brother's keeper and support even if modest, can be readily obtained. [20] Even in misery, Africans are known to be generous in their traditional hospitality. Usually, the community takes over from where the extended family care ends, in providing succor to the less fortunate members of society under the age-old parlance of being "your brother's keeper. [20] It could also be that culturally, Africans tend to cover-up family challenges and present the picture that all is well to an on-looker.

The study showed that of $262(85.0 \%)$ respondents that engaged in self medication for acute febrile illness, 239 $(91.2 \%)$ were from highly functional families and $23(8.8 \%)$ from dysfunctional families. Of the 46 respondents who did not engage in self medication, all were from highly functional families and none from dysfunctional families (Table 4). The difference was statistically significant $(\mathrm{p}=0.037, \mathrm{OR}=1)$. The tendency was that dysfunctional families were more likely to engage in self medication for acute febrile illness.

The result showed that majority of the families had between 1 and 10 members. About 8.4\% of the families had 11 or more members. There was no significant association between family size and self medication. This is in contrast to a study from South West Ethiopia which revealed that families with five or less members were less likely to engage in self medication compared to families with more members. [21] In the Ethiopian study, poverty and illiteracy were prominent amongst the participants. Also, the poorer families tended to have more members. Self medication by poor large families could have been a self help strategy to enable them meet their medication needs at less cost.

This study is limited by the fact that it is a hospital based rather than community based study hence caution should be exercised when applying findings to the community. Data collected was also based on self reported information or recall by the patient and so could be open to bias.

\section{Conclusion}

This study revealed a high (85\%) prevalence of self medication for acute febrile illness among the respondents. The study also revealed relatively low level of family dysfunction $(7.5 \%)$ and a statistically significant association between family function and self medication for acute febrile illness $(\mathrm{P}=0.037, \mathrm{OR}=1)$. It can therefore be inferred that dysfunctional families were more likely to engage in self medication for acute febrile illness.

This implies that physicians ought to be aware of the high prevalence of self-medication for acute febrile illnesses as patients present in their outpatient departments and emergency rooms. The link between family dysfunction and self-medication ought to make physicians to screen for self medication use when faced with dysfunctional families. The reverse is also true: screen for dysfunctional family issues when faced with self medicating patients. Future researchers should consider looking into the contribution of core family factors (for instance divorce, bereavement etc) in self medication.

\section{Acknowledgement}

The authors wish to acknowledge the support of Mrs. Charity O Azonobo.

\section{References}

[1] Kieglast PJ, Jamison AJ, Hoek AJM, Reinstein JA. Responsible Self- Medication: Joint Statement by International Pharmaceutical Federation and World Selfmedication Industry. 10th June, 1999, p1. http://www.wsmi.org/pdf/fip.pdf. Accessed 22-3-2012

[2] Mehra S, Meek S, Boughton J, Vaderick C, Sintasath D: Malaria Consortium. Childhood Illnesses. Accessed 20/02/2012 from

http://www.malariaconsortium.org/pages/childhood_illnesses. htm, 2012.

[3] Oshikoya KA, Njokanma OF, Bello JA, Ayorinde EO; Family self-medication for children in an urban area of Nigeria. Paediatric and Perinatal Drug Therapy, 2007; 8(3):124-30.

[4] Bojang KA, Obaro S, Morison LA, Greenwood BM. Prospective evaluation of a clinical algorithm for the diagnosis of malaria in Gambian children. Trop Med Int Health. 2000; 5(4):231-6.

[5] WHO (2000a). Roll Back Malaria Partnership Secretariat, The Abuja declaration and the Plan of Action in The Africa Summit on Roll Back Malaria. 2000. 
[6] Guerin PJ, Olliaro P, Nosten F, Druilhe P, Laxminarayan R, Binka F, et-al; Malaria, current status of control, diagnosis, treatment, and a proposed agenda for research and development. The Lancet Infectious Diseases, 2002;2(9):56473.

[7] Okeke TA and Okafor HU. Perception and Treatment Seeking Behavior for Malaria in Rural Nigeria: Implications for Control. J Hum Ecol. 2008; 24(3):215-22.

[8] Hopkins H, Talisuna A, Whitty C, Staedke SG. Home Management of Malaria, WHO; Impact of home-based management of malaria on health outcomes in Africa: a systematic review of the evidence. Malar J. 2007;6:134.

[9] Chudhuri S. Social development and the family. Available at http://www.eolss.net/sample-chapters/c11/e1-11-02-04.pdf. Retrieved on 30/12/2012

[10] Campbell TL. The effectiveness of family interventions of physical disorders; Journal of Marital and Family Therapy. 2003;29(2):263-81.

[11] Bray JH, Campbell TL. The Family's Influence on Health. In: Rakel RE (ed). Rakel textbook of family medicine, 2007: 7th edition, Saunders; Philadelphia. Pp 25-34.

[12] McDaniel HS, Campbell TL, Hepworth J, Lovenz A. Familyoriented primary care; Springer; 2nd edition, 2005; New York. p3.

[13] Chaturvedi HK, Mahanta J, Pandey A. Treatment-seeking for febrile illness in North-East India: an epidemiological study in the malaria endemic zone. Malar J 2009; 8:30.
[14] Deressa W, Ali A, Enqusellassie F. Self-treatment of malaria in rural communities, Butajira, southern Ethiopia. Bull World Health organ. 2003; 81(4):261-8.

[15] Chukwuocha AN, Chukwuocha UM. The continued relevance of home management of malaria strategy in the effective and sustainable control of malaria in endemic areas; Scientific Research and Essays 2011; 6(33):6748-53.

[16] Stoop D, Masteller J. Forgiving Our Parents, Forgiving Ourselves: Healing Adult Children of Dysfunctional Families. Regal. California. 2011; Pp 7-17.

[17] Araoye MO. Text book on Research Methodology with statistics for Health and Social Sciences. Nathadex, Ilorin, Nigeria. 2003. Pp 118-9.

[18] Pequegnat W, Bray JH. Families and HIV/AIDS: Introduction to the special section. Journal of Family Psychology, 1997; 11(1):3-10.

[19] Jaina p, Sachanb A, Singlac RK, Agrawala P. Statistical Study on Self Medication Pattern in Haryana, India. Indo Global Journal of Pharmaceutical Sciences, 2012; 2(1):21-35.

[20] Panapress. Where is the traditional African hospitality? Jun 27, 2001 - Dakar- Senegal (PANA). Available at: http://www.panapress.com/Where-is-the-traditional-Africanhospitality. Accessed 2013-10-09.

[21] Mussa S, Gedif T. Antimalarial Drug Use Pattern in Pawe Special Woreda, North West Ethiopia: A Community Based Survey. Ethiopian Pharmaceutical Journal. 2011;29(2):121-36. 